REGETAUFSM MANÉIA \& KROHLING, v(7), no 7, p. 1540-1554, MAR-AG0, 2012.

Rev. Elet. em Gestão, Educação e Tecnologia Ambiental (e-ISSN: 2236-1170)

\title{
TRANSVERSALIDADE, MEIO AMBIENTE E SUSTENTABILIDADE NA FORMAÇÃO DO EDUCANDO
}

\author{
Arismar Manéia ${ }^{1}$, Aloisio Krohling ${ }^{2}$ \\ ${ }^{1}$ Mestre em Tecnologia Ambiental pela Faculdade de Aracruz-ES. Mestre em Ciências da Educação. Pós graduado em \\ Filosofia e Graduado em Ciências e Graduando em Ciências Sociais. E-mail: arismarmaneia12@hotmail.com \\ 2 Pós-Doutor em Filosofia Política, doutorado em Filosofia pelo Instituto Santo Anselmo em Roma. Mestre em \\ Sociologia Política (Escola de Sociologia e Política de São Paulo). Professor e pesquisador do Programa de Mestrado da \\ FDV e do Programa de Mestrado em Ciências Sociais do Centro Universitário Vila Velha (UVV-ES), E-mail: \\ krohling@gmail.com
}

\section{RESUMO}

A Educação Ambiental em sua transdisciplinaridade é um caminho para fazer exercer possibilidades para se alcançar um modo do ser humano preservar o meio ambiente através da educação com a utilização de conceitos e fundamentos sociológicos básicos. Além de princípios da ética rizomática e da Educação Ambiental, sugere-se uma proposta metodológica que atenda ao objetivo de inserir a perspectiva ambiental nos conteúdos do programa de Sociologia da Educação. Acredita-se que as informações trabalhadas no Curso de Pedagogia sensibilizem o novo pedagogo a exercer seu importante papel de educador difundindo a ideia de inter-relação harmônica ser humano-meio ambiente, de modo a alcançar a meta de redução dos danos socioambientais. Os conteúdos trabalhados nesta proposta podem promover a mudança de atitudes por meio do conhecimento, de modo a informar e a formar nos educandos uma consciência de cidadania comprometida, voltada para o uso racional e prático da sustentabilidade consciente.

Palavras-chaves: Educação Ambiental, Pedagogia, Holismo, Sociologia da Educação.

\section{ABSTRACT}

Environmental Education in its transversality with Sociology of Education is the key to prepare the graduate School of Aracruz (FAACZ) for a holistic view of environmental conservation through education. With the use of concepts and theorical base, important and necessary, it suggests an alternative methodology that meets and understands the development of environmental education program in Sociology of Education. Information used support the idea of sensitizing the new pedagogue, to that in his important role as an educator and disseminator of man's relationship with the environment, conducive for harmonious and transparent in order not to cause social harm. We want to demonstrate that all efforts in this direction will only have value when the man can change his behavior with the intention of improving their knowledge, with the help of the teacher, who must develop, based on their wisdom, their motivation, with planning and systematization, the noble task of effectively multiplying your main goal, which is to get students to form a sense of citizenship committed to the rational use of natural resources.

Keywords: Environmental Education. holistic view. Sociology of Education INTRODUÇÃO 


\section{REGEJ AUFSM MANÉIA \& KROHLING, v(7), no 7, p. 1540-1554, MAR-AGO, 2012.}

Rev. Elet. em Gestão, Educação e Tecnologia Ambiental (e-ISSN: 2236-1170)

A inserção de novos valores na educação relacionados à questão ambiental impele o professor a uma forma nova de conduzir o processo pedagógico visando erigir uma cultura que promova no educando o sentimento de pertencimento ao ambiente natural. Este estudo propõe uma metodologia calcada na inserção transversal dos conteúdos e princípios da Educação Ambiental na disciplina de Sociologia da Educação no curso de Pedagogia, destacando a importância da formação de educadores (pedagogos) ambientais que trabalham temáticas ambientais na escola.

Nas relações do cotidiano a escola tem a possibilidade de proporcionar experiências nas quais os alunos possam construir outras representações de ambiente. A cultura encontra na educação elementos necessários para construção do processo de Educação Ambiental, estimulando os indivíduos a se sentirem parte do ambiente e os professores devem basear a práxis pedagógica em Educação Ambiental pautada na relação entre a teoria e a prática, vislumbrando aprendizagens significativas.

O problema sugerido nasce da angústia da sociedade contemporânea que tem urgência em pensar alternativas práticas que assegurem a sobrevivência do planeta, colocando a EA como questão de sobrevivência para a sociedade e para a espécie humana.

Iniciou-se com o seguinte conceito de Educação Ambiental: "Processo de formação orientadora para o desenvolvimento da consciência crítica sobre as questões ambientais e atitudes que levam à participação das comunidades na preservação do equilíbrio ambiental". E, para que se alcance este objetivo, é fundamental uma profunda investigação prática e a capacitação na EA dentro da especialidade de Pedagogia.

Quando se fala em conscientizar por intermédio da transversalidade se pensa em trabalhar não apenas no momento acadêmico da formação do docente, mas ao longo de todo o processo de ensino e aprendizagem na escola. O objetivo de estudo é a Educação Ambiental e o campo de ação a Educação Ambiental como programa transversal no curso de Sociologia da Educação, com enfoque interdisciplinar da EA na Sociologia da Educação. A transversalidade corta a espinha dorsal do conteúdo da Sociologia da Educação e deve ser um meio para a construção de uma sociedade justa, com relações sociais pautadas pela ética. Então, surge a questão: Como a Sociologia da Educação pode contribuir com o desenvolvimento da EA dos alunos da especialidade de Pedagogia da Faculdade de Aracruz (FAACZ-ES)?

\subsection{A PRODUÇÃO DO CONHECIMENTO NA CONCEPÇÃO RIZOMÁTICA}

O conhecimento rizomático é uma concepção do filósofo francês Gilles Deleuze que aborda a construção do conhecimento numa perspectiva horizontal em diálogo com outras ciências e as novas tecnologias digitais como inter-relacionadas num feixe de raízes, onde nenhuma raiz predomine e onde não haja verticalidade de uma raiz central e onde todos as áreas do saber dialoguem na busca da educação libertadora, tendo como objetivo educacional a consciência ecológica.

Para Deleuze (1995), o conhecimento com princípios rizomáticos sempre possui múltiplas entradas e permite rupturas, ou seja, não pressupõe significações ou valores preestabelecidos, permitindo linhas de fuga, transformações e religações, em suma, novas interfaces. São conhecimentos que apontam em várias direções, elaborando mapas que são sempre 


\section{REGETAUFSM MANÉIA \& KROHLING, v(7), no 7, p. 1540-1554, MAR-AGO, 2012.}

Rev. Elet. em Gestão, Educação e Tecnologia Ambiental (e-ISSN: 2236-1170)

reconstruídos com novas configurações, sempre voltados para a experimentação a partir do real. Nesse caso, o circuito, o "mapa é aberto, é conectável em todas as suas dimensões, desmontável, reversível, suscetível de receber modificações constantemente" (DELEUZE; GUATTARI, 1995, p. 22).

Esse modelo implica na possibilidade de (re) montar o currículo tradicional, de ir além do esquema curricular e elaborar novas possibilidades de articulação, de redes de conhecimentos, abertas, que possam ter muitas conexões, estimulando a criatividade e a imaginação.

Assim, o conhecimento enquanto rizoma é mais rico, complexo e com potencial libertário, contrastando e rompendo com o conhecimento estruturado de forma arbórea, que é de fácil circunscrição e reprodução, com tendência à homogeneização e à padronização e, por isso, muito utilizado nas práticas tradicionais de ensino nas escolas. O rizoma pressupõe horizontalidade e encontro de consciências na intersubjetividade dos atores envolvidos no processo histórico educacional.

O conhecimento elaborado pelo paradigma cartesiano da árvore é um saber sob controle, enquanto o conhecimento cujo paradigma é o rizoma facilita as linhas de fuga, as rupturas e a formação de conexões imprevistas, levando a novas direções. Essa nova forma de articulação do conhecimento rizomático possibilita entendimento e análise transversais, isto é, não é uma abordagem não vertical e autoritária.

São novas percepções e significações que permitem que o processo de conhecer seja conjugado por meio de diferentes saberes, com articulação sem início e sem fim. É um modelo bem diferente do conhecimento arbóreo, isto é, da "árvore do conhecimento", que pode ser, no máximo, multidisciplinar ou pluridisciplinar, na perspectiva de um agrupamento de saberes, ou de áreas do conhecimento, com seus limites definidos, mas não de transversalidade e transdisciplinaridade.

O conhecimento visto enquanto rizoma, trabalhado no processo de ensino nas escolas, pode ser até revolucionário, pois não só implica a mudança paradigmática, como, também, reflete uma mudança radical na dinâmica pedagógica. Nesse sentido, pode-se dizer que altera a relação professor aluno: se não há hierarquia, formatação, unidade e modelo nos saberes, o professor tanto ensina quanto aprende. Aqui cabe aquela máxima do nosso grande educador Paulo Freire: "ninguém ensina a ninguém, ninguém aprende sózinho, nos nos educamos uns aos outros mediante o mundo da vida.

\subsection{EDUCAÇÃO AMBIENTAL RIZOMÁTICA}

A prática do paradigma rizomático do conhecimento cria espaço, proporciona condições para um novo enfoque didático-metodológico em que o educador aumenta as possibilidades de trabalhar com seu aluno de modo criativo, construindo novos saberes, em um espaço de liberdade, e de, assim, subverter, transformando o conhecimento arbóreo em conhecimento com característica rizomática. Ou seja, rompe-se com a rigidez dos currículos, com a ritualização e repetição didática do professor e com a passividade reprodutora do aluno. 


\section{REGETAUFSM MANÉIA \& KROHLING, v(7), no 7, p. 1540-1554, MAR-AGO, 2012.}

Rev. Elet. em Gestão, Educação e Tecnologia Ambiental (e-ISSN: 2236-1170)

A dimensão ambiental na educação socioambiental está no contexto prático da formação de professores desde o momento que se percebeu a necessidade de preparar os futuros professores, a transmitir não só conhecimentos, mas princípios e valores relacionados ao meio ambiente. Uma leitura histórica da educação no Brasil, em 1971 aponta para a criação de um modelo de educação dirigido à formação de professores especialistas, fundamentado no desenvolvimento das funções técnicas, que excluía a globalidade, o subjetivismo e a crítica como já mencionado.

O papel da educação se forma em meio a conflitos, dogmas, ideologias e dúvidas, geradores de angústia. $O$ indivíduo se forma na prática, através de atividades que promovem a transformação social.

Gadotti $(1998$, p. 68) insiste na forma de aprendizagem com a prática, tendo em vista estabelecer conhecimentos que desmitificam o poder de uma relação docente atuando na prática pedagógica.

Hoje se deve pensar na tarefa do educador como aquele que provoca, evidencia e trabalha com os conflitos. Pensar e atuar com a Pedagogia é predispor positivamente não somente aos nossos educandos, também a toda comunidade escolar.

Para Snyders (1998, p. 83), a escola deve absorver e perseguir as perspectivas discutidas, assim abrirá horizontes culturais, linguagens, modos de pensar em um mundo cada vez mais próximo ao desejado e contribuindo para uma sociedade cada vez melhor.

A Educação Ambiental e a prática social não podem estar dissociadas, pois essa ruptura comprometeria as possibilidades de maiores conquistas no processo de formação das novas gerações. Isto significa que a formação ambiental inicial dos professores deve incluir por si todas aquelas características e qualidades que a sociedade necessita realizar nas escolas.

Mas que formação? Uma que supere as propostas que proliferam de formar multiplicadores para educação ambiental, fundamentada na ética como matriz

rizomática do princípio originário e fontal da dignidade da pessoa humana e dos princípios rizomáticos dos direitos humanos fundamentais. (KROHLING,Aloisio. Ética da Alteridade e da Responsabilidade. Curitiba: Juruá, 2011.)

A educação destes educadores deve ser pensada em uma perspectiva ética crítica de modo a que compreendam a complexidade dos processos (movimentos) sociais, motivados pela reflexão crítica, mobilizem (mobilização = ação em movimento - práxis), com sinergia, processos de intervenção sobre as dinâmicas constituídas e constituintes da realidade socioambiental.

Como afirma Grzybowski (1991, p. 27), "atualmente, há uma disputa de hegemonia e nós (educadores) somos atores centrais nisso, queiramos ou não. A serviço de nosso próprio projeto, conscientes de nosso projeto, ou a serviço do projeto dos outros".

É o que Paulo Freire entende como saída da "imersão" para uma "inserção crítica", tanto do educando quanto do educador. Na "imersão" em que se encontram, não podem os oprimidos 


\section{REGETAUFSM MANÉIA \& KROHLING, v(7), no 7, p. 1540-1554, MAR-AGO, 2012.}

Rev. Elet. em Gestão, Educação e Tecnologia Ambiental (e-ISSN: 2236-1170)

divisar, claramente, "A "ordem" que serve aos opressores que, de certa forma, 'vivem' neles" (FREIRE, 1992b, p. 49).

Edgar Morin (1988), em suas reflexões, fala da noção de resistência, brecha e regeneração. como um movimento de ruptura, de construção do novo, das transformações socioambientais.

Educação ambiental não é apenas comunicação ambiental. Estabelecer uma equivalência entre educação e comunicação é acreditar que apenas a transmissão da informação ambiental seja suficiente para proporcionar a transformação individual e coletiva da sociedade, e que a transmissão da informação ambiental correta terá como reflexo uma mudança de comportamento individual e, consequentemente, social diante da natureza.

Não se está se referindo aqui à comunicação existente na dialogicidade (diálogo, do grego dialogos- fluxo de significados), mas à comunicação como transferência unidirecional de um para outro, o que Freire chama de "comunicado". Essa é uma visão reduzida da educação e que se amolda àquela visão mais conservadora que, ao não promover as transformações, ajusta-se à reprodução do status quo. A informação é para ser trabalhada e não apenas transmitida. "Ensinar não é transferir conhecimento, mas criar as possibilidades para a sua produção ou a sua construção" (FREIRE, 1997, p. 25).

O conhecimento transmitido remete ao conhecimento de realidades passadas: se não for utilizado para instrumentalizar uma ação transformadora, tende a reproduzir e, portanto, a conservar situações passadas-comunicação (transmissão de conhecimento), está contida em um processo educacional, mas esse não pode parar por aí, se a intenção é impulsionar um processo de transformação social que rume para a construção da sustentabilidade ambiental.

O ambiente educativo deve buscar religar a escola aos movimentos sociais, como exercício de cidadania dos educadores e formação de cidadania dos educandos, em um esforço de superação da dicotomia entre escola e comunidade. A aprendizagem significativa, capaz de causar transformações, se dá na inserção do indivíduo no coletivo, atuando no processo de transformações sociais e sendo transformado pela experienciação de novas relações na construção de novas realidades.

Morin (2000a, p. 72) contribui com estas reflexões ao afirmar que: "Frequentemente, na história, contracorrentes suscitadas em reação às correntes dominantes podem se desenvolver e mudar o curso dos acontecimentos". Esse pode ser um mecanismode trabalharmos a autoestimae a valorização de sua função social, a confiança na potencialidade transformadora de sua ação pedagógica articulada a um movimento conjunto. Este é um movimento de empoderamento.

A formação ambiental está amparada por lei, mas o problema é que muitos professores não se sentem à vontade para desempenhá-la. A Proposta de Diretrizes Curriculares Nacionais (PCN) para a EA, em suas diretrizes, faz referência à formação crítica continuada destes professores em formação, acentuando a necessidade de incluir atividades, projetos, incluindo conhecimentos e práticas pedagógicas com ações interdisciplinares, cooperativas, investigativas e transformadoras da EA. Sendo assim, se entende que o ensino na Pedagogia, em especial representada pelo grupo 


\title{
REGETAUFSM MANÉIA \& KROHLING, v(7), no 7, p. 1540-1554, MAR-AGO, 2012.
}

Rev. Elet. em Gestão, Educação e Tecnologia Ambiental (e-ISSN: 2236-1170)

Rev. Elet. em Gestão, Educação e Tecnologia Ambiental (e-ISSN: 2236-1170)

da FAACZ, pode avançar muito em relações às dimensões dos problemas socioambientais e nas preocupações para a busca de conceitos necessários para uma qualidade no ensino ambiental.

\subsection{A ÉTICA RIZOMÁTICA}

As dificuldades ecológicas enfrentadas na atualidade,de acordo com Junges (2006), solicitam, diante dos recursos técnicos, uma resposta ética, requerendo uma mudança de paradigma civilizatório, referente à convivência social, a vida pessoal e, também, na produção de bens de consumo, mas, sobretudo, do relacionamento com a natureza. Para este autor, "A discussão ética no âmbito da ecologia surgiu como resposta a esse contexto e como reação a uma mentalidade predatória da natureza" (JUNGES, 2006, p. 12).

KROHLING, Aloisio. Paper resumo expandido nos Anais no Simpósio de Filosofia do Direito. ABRAFI. Belo Horizonte, 24 e 25 de novembro de 2011).

Afirma o seguinte:

\begin{abstract}
Os novos direitos estão relacionados ao resgate do meio-ambiente, isto é à redescoberta do Planeta-Terra. O direito à cosmicidade implica na tese da sustentabilidade e da ética ecológica. A modernidade da razão instrumental e o avanço da tecnologia levaram ao mito do progresso que por sua vez desembocou na destruição da natureza. Hoje em dia cresce uma nova consciência ética ecológica que clama por uma política de educação ambiental em todos os níveis e em todos os continentes. A ética de novo se torna a nova base para a reconstrução do mundo sóciopolítico e o mundo da vida e da política e condição necessária para a sobrevivência da espécie humana. Presenciamos a redescoberta da ética da alteridade, da responsabilidade, da cosmicidade, da corporeidade, do princípio da vida, do princípio fontal da dignidade da pessoa humana e outros princípios rizomáticos do Direito.
\end{abstract}

A ética ambiental surge no debate ecológico expondo questões fundamentais, discutindo o próprio ponto de partida e abrangência dos sujeitos de consideração à mesma. Não é criação humana, mas sistematização de normas inscritas na natureza, "onde a existência e a conservação de uma espécie são subordinadas aos equilíbrios entre os processos destrutores e regeneradores e seu meio", como afirma o geógrafo francês Pierre Jorge (1966 apudReigota, 2006, p. 20). De modo que cabe aos seres humanos se darem conta dessas normas e ajustarem o seu comportamento aos equilíbrios de forças concorrentes que condicionam a vida do grupo biológico.

A ética ecológica, na opinião de Boff (2003, p.85), deverá ser a "ética do cuidado", pois:

O cuidado expressa a importância da razão cordial, que respeita e venera o mistério que se vela e revela em cada ser do universo e da Terra. Por isso, a vida e o jogo das relações só sobrevivem se forem cercados de cuidado, de desvelo e de atenção.

Segundo Assman (1998), a consideração ética a respeito do meio ambiente não é mais um tema a ser acrescentado ao currículo, pois se tornou uma necessidade associada com o sentido mais humano do que é ser humano. A Educação Ambiental, muitas vezes, tem sido sinônimo de informações de livros didáticos, plantio de árvores, coleta de lixo seletivo, criação de hortas. 


\title{
REGETAUFSM MANÉIA \& KROHLING, v(7), no 7, p. 1540-1554, MAR-AGO, 2012.
}

Rev. Elet. em Gestão, Educação e Tecnologia Ambiental (e-ISSN: 2236-1170)

\begin{abstract}
Aloisio Krohling ( idem, 2011)fortalece este conteúdo assegurando:
A Ética é sempre cuidado e respeito à alteridade e pretende a perfeição do ser humano, que não se realiza sozinho. A Ética é sempre a redescoberta de si mesmo ou do OUTRO. Ninguém perde a sua ipseidade se relacionando com outras pessoas. Pelo contrário realiza-se o encontro entre duas pessoas que se completam na mutualidade e reciprocidade.
\end{abstract}

Devido ao fato de a maioria dos professores não estar preparada com informações e formação adequada, acaba por utilizar exemplos que se afastam da realidade cotidiana, situações descontextualizadas, abordando conteúdos que, na prática, poderiam ser explorados na própria região, valorizando a cultura, a história e os problemas ambientais do município.

A ética ambiental analisa nossos deveres morais diante dessas questões: quais os direitos e obrigações que temos quanto ao meio ambiente, e os temos por quê? Parece que temos obrigações de cuidado ambiental derivadas do respeito (i) aos que, como nós, vivem hoje, (ii) aos que viverão no futuro e (iii), também, a entidades do próprio ambiente (AZEVEDO, 2010, p. 4). Há filósofos e ambientalistas se dedicando a cada um desses compartimentos e há muito bom material produzido. Um fato importante é que os avanços do conhecimento científico a respeito do funcionamento de biomas e ecossistemas podem influenciar muito as posições, atitudes e estratégias da ética ambiental.

Aética ambiental poderá tornar-se natural e espontânea, sem a necessidade da aplicação de normas legais, porque se transformará na conviç̧ão e manifestação conjunta de todos os habitantes do planeta Terra (FREIRE, 2000, p. 31):

\begin{abstract}
[...] o fato em si de mais esta trágica transgressão de ética nos adverte de como urge que assumamos o dever de lutar pelos princípios éticos mais fundamentais como do respeito à vida dos seres humanos, à vida dos outros animais, à vida dos pássaros, à vida dos rios e das florestas.Não creio na amorosidade entre mulheres e homens, entre os seres humanos se não nos tornamos capazes de amar o mundo.A ecologia ganha uma importância fundamental neste fim de século.Ela tem de estar presente em qualquer prática educativa de caráter radical, crítico ou libertador.
\end{abstract}

Leonardo Boff (1999) alerta que para cuidar do planeta precisamos todos passar por uma alfabetização ecológica, rever nossos hábitos de consumo. Importa desenvolver uma ética do cuidado que perpassa pela formação do pedagogo e da ressignificação dos processos formativos, saberes e práticas sociais que engendram o trabalho educativo comprometido com a construção de uma sociedade justa, igualitária e com qualidade de vida. Isso pode se dar por meio da inserção da Educação Ambiental na formação de pedagogos.

\subsection{CONCLUSÃO}

Sendo a Pedagogia um campo de conhecimento que envolve várias disciplinas, que agrega contributos de várias áreas de conhecimento - sobretudo das Ciências Humanas -, a Sociologia da Educação traz fundamentação de diversas disciplinas que fazem parte do currículo do curso de Pedagogia. 


\section{REGETAUFSM MANÉIA \& KROHLING, v(7), no 7, p. 1540-1554, MAR-AGO, 2012.}

Rev. Elet. em Gestão, Educação e Tecnologia Ambiental (e-ISSN: 2236-1170)

A formação profissional do professor iniciou-se com a criação da Escola Normal em todo o Brasil, preparando professores para transmitir conhecimentos. Em 1971 surge a formação de professores especialistas, fundamentada no desenvolvimento tecnológico da época, passando por um período de desatenção para a educação humana.Mas, a partir dos anos 1980, ganha uma atenção especial, porque os educadores envolvem-se em mudanças curriculares para o curso de Pedagogia, propondo uma formação mais globalizada.

O papel do professor passa a ser uma prática pedagógica crítica e consciente. Assim, procurou-se uma abordagem nova para a concepção do professor, do aluno, do processo e da sociedade como um todo. Portanto, o tema na formação do professor busca um desempenho escolar em uma sociedade pluralista, preparando cidadãos críticos, solidários e respeitosos com o meio ambiente.

É preocupante perceber a distância entre as exigências de conhecimentos da sociedade e a capacidade insuficiente que as escolas oferecem aos alunos. É importante criar um ambiente que estimule o apoio e a cooperação entre os professores acrescidos de treinamentos, com: definição de novos rumos para o trabalho com meio ambiente, criação de condições para o professor se preparar para a regência, facilitar e apoiar novos aprendizados e criar uma cultura de sucesso.

Por sua vez, o professor deve saber que sua formação é permanente, que precisa desenvolver suas competências e habilidades para as novas exigências da realidade socioambiental, utilizando estratégias de constantes avaliações e aprendizagens. Isso ganha força e destaque com a formação continuada, no âmbito legal, que promulga, em 1996, mudanças profundas no ensino brasileiro. Demonstra-se, portanto, neste período, a grande preocupação com os aspectos principais da formação do professor.

A qualificação (conhecimentos científicos), formação pedagógica e a formação ética e política (educar a partir de valores) passam a ser primordiais para associar teoria e práxis. Assim, a educação em formação e a prática socioambiental não podem ser dissociadas, pois a ruptura destas comprometeria as possibilidades de maiores conquistas no processo de formação de novas gerações para a Educação Ambiental.

A Educação Ambiental (EA) vem se disseminando no ambiente escolar brasileiro. Há uma crescente inserção em resposta às expectativas que a sociedade projeta sobre a escola. A institucionalização da EA, que vem se processando, reflete a demanda da sociedade e, reciprocamente, pressiona as escolas a desenvolverem ações que denominam de Educação Ambiental. Portanto, a EA já é uma realidade para os professores e estes estão fazendo, ou se sentem compelidos a se debruçar sobre essa nova dimensão educativa.

A primeira questão que se coloca é que, apesar da difusão crescente da EA pelo processo educacional, essa ação educativa reconhecida como Educação Ambiental geralmente se apresenta fragilizada em sua prática pedagógica. Fragilizada por considerar que a superação da crise ambiental passa pelo processo de profundas transformações socioambientais e, para contribuir nesse processo, a EA precisa assumir caráter crítico-transformador.

Os professores, na maior parte das vezes, estão preocupados com a degradação da natureza, mobilizam-se com empenho sincero para enfrentar essa questão, mas as práticas resultantes, 


\section{REGETAUFSM MANÉIA \& KROHLING, v(7), no 7, p. 1540-1554, MAR-AGO, 2012.}

Rev. Elet. em Gestão, Educação e Tecnologia Ambiental (e-ISSN: 2236-1170)

geralmente, são pouco eficazes para atuar, de forma significativa, no processo de transformação da realidade mais imediata com a qual estão lidando e, reciprocamente, com uma realidade mais ampla (GUIMARÃES, 2004, p. 120).

Os professores não conseguem ir além de uma proposta de educação, que eles mesmos denominam de conservadora, mesmo quando sensibilizados e motivados a inserir a dimensão ambiental em suas práticas educativas (GUIMARÃES; IN FORSATO, 2010, p. 321). Esta é a motivação para o assunto abordado nesta dissertação,que averigua o movimento coletivo de questionamento das práticas escolares dominantes. Isso para pensar um novo fazer pedagógico voltado para a transformação, a criação e a construção de um novo mundo que seja ambientalmente (em sua concepção plena) sustentável. Estas reflexões têm a intenção de discutir o que Guimarães (2004) denomina eixos formativos, importantes para orientar os trabalhos de formação de educadores ambientais, aptos a participar da construção de ambientes educativos dentro de uma perspectiva crítica.

Caminha-se na perspectiva de que a crise ambiental é produto histórico de uma sociedade que constitui paradigmas (e é constituída por eles) que, dominantemente, informam a compreensão de uma realidade e, reciprocamente, formam essa realidade, tanto pela ação sobre essa realidade informada por esses paradigmas, quanto pela que reforça esses paradigmas por meio da ação informada por eles.

Sendo assim, acredita-se que, para superar a crise ambiental da atualidade, é necessário superar os paradigmas e o modelo de sociedade com suas múltiplas determinações que reciprocamente se produziram. Isso se faz pelo engajamento ao movimento de reflexão crítica a essa realidade estabelecida em sua complexidade e pela participação na construção do devir utópico, no sentido freireano (FREIRE, 1992, p. 73):

[...] utopia como unidade inquebrantável entre a denúncia e o anúncio. Denúncia de uma realidade desumanizante e anúncio de uma realidade em que os homens possam ser mais. Anúncio e denúncia não são, porém, palavras vazias, mas compromisso histórico.

A participação na construção deste devir utópico, motivada pela reflexão crítica, significa estar inserida essa crítica nas múltiplas determinações do modo de produção capitalista de que fala Marx, entre estas as determinações epistemológicas, ético-políticas e materiais. Portanto, a transformação da realidade social e de seus indivíduos passa pela transformação recíproca dessas múltiplas determinações.

A Educação Ambiental é, portanto, uma prática pedagógica que não se realiza sozinha, mas nas relações do ambiente escolar, na interação entre diferentes atores, conduzida por um sujeito: o professor. Para Carvalho (2001, p. 74):

Um sujeito que pode ser visto em sua versão grandiosa como um sujeito heróico, vanguarda de um movimento histórico, herdeiro de tradições políticas de esquerda, mas protagonista de um novo paradigma político-existencial; em sua versão new age é visto como alternativo, integral, equilibrado, harmônico, planetário, holística; e também em sua versão ortodoxa, na qual é suposto aderir a um conjunto de crenças básicas, uma espécie de cartilha - ou ortodoxia - epistemológica e política da crise ambiental e dos caminhos para enfrentá-la. 


\section{REGETAUFSM MANÉIA \& KROHLING, v(7), no 7, p. 1540-1554, MAR-AGO, 2012.}

Rev. Elet. em Gestão, Educação e Tecnologia Ambiental (e-ISSN: 2236-1170)

Esses professores foram ou estão sendo formados, em sua maioria, na mesma perspectiva conservadora de educação que reproduz e se reproduz na armadilha paradigmática ${ }^{2}$. Ou seja, dada uma compreensão de mundo moldada pela racionalidade hegemônica, geram-se práticas, entre elas a ação discursiva, incapazes de fazer diferente do "caminho único" prescrito por essa racionalidade, efetivando-se a hegemonia. Guimarães (2004) usa como metáfora a correnteza de um rio: se não houver, de parte, um esforço para se mudar de rumo, ser empurrado e seguir na direção da correnteza. Consolida-se, assim, entre os professores, um habitus de uma prática conservadora de educação, mesmo na educação ambiental.

Bordieu (1983, p. 66) afirma que:

Pelo fato de que a identidade das condições de existência tende a produzir sistemas de disposições semelhantes (pelo menos parcialmente), a homogeneidade (relativa) do habitus que delas resulta está no princípio de uma harmonização objetiva das práticas e das obras, harmonização esta própria a lhes conferir a regularidade e a objetividade que definem sua 'racionalidade' específica e que as fazem ser vividas como evidentes e necessárias, isto é, como imediatamente inteligíveis e previsíveis, por todos os agentes dotados do domínio prático do sistema de esquemas de ação e de interpretação objetivamente implicados na sua efetivação, e por esses somente.

Da mesma forma, essa armadilha paradigmática (que se reflete nas práticas de educação ambiental no cotidiano escolar e também na formação desses professores), vai influenciar os autores que produzem os livros didáticos que tanto dão suporte aos professores no seu dia a dia, e nos quais geralmente predomina uma abordagem conservadora sobre a EA. Sendo assim, essa armadilha paradigmática repercute diferentes espaços sociais.

Essa fragilidade da prática pedagógica em educação ambiental questionava se ela se dava por falta de formação dos professores para a EA, por falta de espaços de discussão sobre EA na sociedade, que propiciassem uma formação continuada a esses professores, por falta de uma produção acadêmica voltada para essa dimensão educativa ou por falta de materiais didáticos para o desenvolvimento dessa prática pedagógica no cotidiano escolar.

No final, afirma-se que essas questões devem ser consideradas em seu conjunto, pois, isoladamente, nenhuma delas explica a fragilidade da EA nas escolas, já que essa armadilha paradigmática se produz e reproduz dominantemente, nos diferentes espaços sociais, exercendo sua hegemonia (BOURDIEU, 1983).

Isso se agrava quando os paradigmas dominantes da sociedade moderna em sua racionalidade reforçam a visão fragmentada, dualista e dicotômica de mundo, naturalizando a separação entre refletir e agir. Daí a importância da práxis como reflexão e ação, teoria e prática se realizando reciprocamente na constituição de um novo paradigma em conjunto com a construção de uma sociedade ambientalmente sustentável. .

Os paradigmas e a racionalidade moderna se apresentam hegemônicos no ambiente escolar, levando os professores a reproduzi-los em suas práticas, fragilizando seus objetivos de trabalhar as questões ambientais. Por suas limitações compreensivas, reducionistas e simplificadoras da

\footnotetext{
${ }^{2}$ Guimarães (2004)
} 


\title{
REGETAUFSM MANÉIA \& KROHLING, v(7), no 7, p. 1540-1554, MAR-AGO, 2012.
}

Rev. Elet. em Gestão, Educação e Tecnologia Ambiental (e-ISSN: 2236-1170)

realidade, Ihes são veladas as causas profundas (raiz - radicalidade) que se encontram nas relações de dominação e que atrelam a constituição dos problemas ambientais da atualidade ao modelo de sociedade moderna, com seus paradigmas e sua racionalidade (SANTOS; SATO, 2001, p. 121)

\begin{abstract}
Na esfera da racionalidade hegemônica, pequena margem é deixada para a variedade, a criatividade e a espontaneidade. Enquanto isso surge nas outras esferas. Contrarracionalidades e racionalidades paralelas corriqueiramente chamadas de irracionalidades, mas que na realidade constituem outras formas de racionalidade.
\end{abstract}

No entanto esse habitus, como uma "subjetividade socializada" (BOURDIEU, 1983), não é um destino imutável e estático, em que percepções e práticas não possam ser transformadas. "Habitus não pode ser interpretado apenas como sinônimo de uma memória sedimentada e imutável; é também um sistema de disposição construído continuamente, aberto e constantemente sujeito às novas experiências" (MARTINS, 1990).

Para Bourdieu (1983), é possível a reorganização das percepções e de novas tomadas de posição pelos agentes sociais. Habitus é também adaptação; ele realiza sem cessar um ajustamento ao mundo que só excepcionalmente assume a forma de uma conversão radical ( $/$ bid).

Qual a forma de romper com as práticas conservadoras de EA que não transformam significativamente a realidade (não mudam o curso do rio) e que vem se tornando comum observar no cotidiano das escolas brasileiras? É fundamental um esforço de ruptura com a armadilha paradigmática que produz a limitação compreensiva e a incapacidade discursiva gerando práticas conservadoras.

Uma forma de gerar essa ruptura se dá na reflexão crítica que informa uma práxis, ou, como diria Morin, na reforma do pensamento como o romper de uma fronteira mental epistêmica. "À visão do universo obediente a uma ordem impecável, é preciso substituir a visão na qual este universo é o jogo e o risco da dialógica (relação ao mesmo tempo antagônica, concorrente e complementar) entre a ordem, a desordem e a organização" (MORIN, 2000a, p. 83-84).

A necessidade de uma reflexão crítica já era apontada por Paulo Freire na década de 1960. Naquela época, a questão ambiental não estava tão presente e, consequentemente, tão explícita em seu discurso. No entanto Freire denunciava uma perspectiva conservadora da educação, caracterizada pelo que denominava de "educação bancária" (FREIRE, 1992b, p. 57):

\footnotetext{
Quanto mais analisamos a relação educador-educandos, na escola, em qualquer de seus níveis (ou fora dela), parece que mais nos podemos convencer de que essas relações apresentam um caráter especial e marcante - o de serem relações fundamentalmente narradoras, dissertadoras. [...] Narração ou dissertação, que implica um sujeito - o narrador - e objetos pacientes, ouvintes - os educandos. [...] Falar da realidade como algo parado, estático, compartimentado e bem-comportado, quando não falar ou dissertar sobre algo completamente alheio à experiência existencial dos educandos vem sendo, realmente, a suprema inquietação dessa educação.
}

\footnotetext{
${ }^{3}$ Em seus últimos trabalhos, Freire incorpora mais explicitamente a dimensão ambiental em suas reflexões, como, por exemplo, em Pedagogia da indignação (2000), publicação post mortem e organizada por Ana Maria Freire.
} 
REGEJ fuTSM MANÉIA \& KROHLING, v(7), no 7, p. 1540-1554, MAR-AGO, 2012.

\section{Rev. Elet. em Gestão, Educação e Tecnologia Ambiental (e-ISSN: 2236-1170)}

"Educação bancária" com características antidialógicas que servem à opressão; opressão essa inerente ao modelo de sociedade moderna, que estabelece relações desiguais de dominação de um indivíduo sobre outros, de classes sociais sobre outras, de nações sobre outras, da sociedade sobre a natureza. A reflexão crítica, como força propulsora da ruptura que se realiza na práxis é radical, (FREIRE, 1992b, p. 25), que vai às raízes:

A radicalização, pelo contrário, é sempre criadora, pela criticidade que a alimenta. Enquanto a sectarização é mítica, por isso alienante, a radicalização é crítica, por isso libertadora. Libertadora porque, implicando o enraizamento que os homens fazem na opção que fizeram, os engaja cada vez mais no esforço de transformação da realidade concreta, objetiva.

A reflexão crítica é questionadora de uma realidade predeterminada: "Toda prescrição é a imposição da opção de uma consciência a outra. Daí, o sentido alienador das prescrições que transformam a consciência recebedora no que vimos chamando de consciência "hospedeira" da consciência opressora" (Idem, ibidem, p. 34).

Portanto, a reflexão crítica não se fia na estabilidade das certezas, do já conhecido; não se acomoda na visão simplificadora e reducionista da realidade, mas vai buscar os nexos contidos nas interações e inter-relações das partes com o todo e do todo com as partes.

Para Freire (1992b), trata-se da "tentativa de uma educação estimulante do pensar autêntico, que não se deixa emaranhar pelas visões parciais da realidade, buscando sempre os nexos que prendem um ponto ao outro, ou um problema a outro" (p. 60).

A reflexão crítica se abre para o novo, para as incertezas, que, tornando-se referências, relativizam as verdades, complexificando-as. Essa reflexão crítica que busca a complexidade permite práticas transformadoras, críticas e criativas, buscando superar a reprodução em um esforço de construção do inédito. Percebendo o real como uma unidade complexa -unitas-multiplex-, "considerado sob o ângulo do todo, é uno e homogêneo; considerado sob o ângulo dos constituintes, é diverso e heterogêneo" (MORIN, 1997b, p. 102).

Ao se discutir a pedagogia das certezas, afirma que a certeza das teorias afasta dos envolvidos uma atitude reflexiva, e complementa: O paradigma da complexidade, como sugere Leff (1999, p. 176), coloca outro desafio para a educação:

Estabelecer um diálogo entre a certeza e a incerteza. "Saber lidar com a incerteza do conhecimento, quer dizer fomentar a capacidade de ver o mundo como sistemas complexos, para compreender a indeterminação, a interdependência e a causalidade múltipla entre os diferentes processos".

Superação não no sentido de negação, apenas do que é anterior, mas no sentido de incorporação e transformação.

A reflexão crítica denuncia as intenções ideológicas de parcializar as análises e acobertar interesses que manipulam a compreensão da realidade, dando-lhe sentido de caminho único (a racionalidade do moderno, centrada na ordem). Nega o embate hegemônico e apresenta as forças contra-hegemônicas como desordem; uma anomalia do processo social(SIMONETTI; RAMOS, 2001). 


\section{REGETAUFSM MANÉIA \& KROHLING, v(7), no 7, p. 1540-1554, MAR-AGO, 2012.}

Rev. Elet. em Gestão, Educação e Tecnologia Ambiental (e-ISSN: 2236-1170)

No embate hegemônico as forças hegemônicas encontram no presente a resistência das forças contra-hegemônicas, e, é na síntese resultante dessa correlação que se estabelece o vir-a-ser, ou devir social. Certamente isso se reflete no cotidiano escolar. Portanto, o discurso escolar não é necessariamente homogêneo - o que há é um esforço ideológico da postura hegemônica de homogeneizar os discursos. Desta feita, as ideias de Freire não são dominantes, mas alimentam forças que resistem e se colocam no embate. A reflexão crítica, ao desvelar essa realidade socioambiental estruturada pelas relações de poder constitutivas das relações entre indivíduos, sociedade e natureza, adquire clareza para guiar uma ação crítica que busque intervir no processo social, em suas múltiplas determinações. Ação crítica transformadora das condições materiais, epistemológicas e ético-políticas, estruturantes da realidade socioambiental.

Para que essa postura represente, de fato, uma ruptura, com transformações significativas em uma intervenção processual, é necessária a sinergia de um movimento conjunto. A ação da parte atitude individual - provoca um fenômeno, mas reduzido e pouco significativo para a transformação do todo. A realidade social não é constituída pelo somatório da realidade de cada indivíduo, como se os indivíduos e suas realidades fossem autônomos em relação ao contexto social (realidade do todo). Há uma imbricação (relação) entre o todo e a parte. No sentido de Influência recíproca e simultânea (GUIMARÂES, 2004).

Segundo o Dicionário Brasileiro de Ciências Ambientais (LIMA; SILVA et al., 1999, p. 214):

Sinergia: fenômeno que ocorre quando a interação de duas causas provoca um efeito total maior do que a soma dos efeitos das duas agindo separadamente. Por extensão, qualidade de qualquer fenômeno no qual um todo é mais ativo, eficiente e produtivo do que a soma de suas partes.

Não há soma de mudanças de comportamentos individualizados que gerem intervenções pontuais - até porque uma intervenção processual (no processo está intrínseco o movimento) é diferente de intervenções pontuais, mesmo que sequenciadas. A intervenção processual em uma realidade socioambiental se dá em um movimento coletivo conjunto que cria, de forma significativa, pela sinergia, uma resistência - como uma contra correnteza que pode transformar a força e o sentido da correnteza do rio.

Ao se exercer, de formacoletiva, a educação ambiental muda-se o curso da história. Na troca interativa de experiências, o diálogo resulta em sinergia e potencializa o movimento em benefício de todos.Aqui, torna-se útil a aplicação do conhecimento rizomático,que possibilita o entendimento e análise transversais, criando condições para um novo enfoque didáticometodológico em que se rompe com a rigidez dos currículos, com a ritualização e repetição didática do professor e com a passividade reprodutora do aluno.

\section{REFERÊNCIAS}

ASSMAN, H. Reencantar a educação: rumo à sociedade aprendente. Petrópolis:Vozes, 1998.

AZEVEDO, Fausto A. de. Ainda uma vez a ética e a ética ambiental. Revista Intertox de Toxicologia, Risco Ambiental e Sociedade, vol. 3, no 2, mar/jun, 2010.

BOFF, L. Ethos mundial: um consenso mínimo entre os humanos. Rio deJaneiro: Sextante, 2003. 


\section{REGEJAUTFSM MANÉIA \& KROHLING, v(7), no 7, p. 1540-1554, MAR-AGO, 2012.}

Rev. Elet. em Gestão, Educação e Tecnologia Ambiental (e-ISSN: 2236-1170)

BOFF, L. Saber cuidar: Ética do humano - Compaixão pela Terra. Petrópolis: Vozes, 1999.

BOURDIEU, Pierre. Questões de sociologia. Rio de Janeiro: Marco Zero, 1983.

BRASIL.Lei de Diretrizes e Bases da Educação Nacional. Lei no 9.394, de 20 de dezembro de 1996. Brasília, DF: 1996.

.Constituição da República Federativa do Brasil. 1988.Disponível em: <http://www.planalto.gov.br/ccivil/Leis/_03/Constituição/Constitui\%E7ao.htm>. Acesso em: 07 set. 2006.

.Parâmetros Curriculares Nacionais, Ensino Fundamental. Disponível em:

<httpl/portal.mec.gov.br/seb/index.php?optionecontentêtask-view\&id=557>. Acesso em: 12 de mar. 2000.

. Secretaria de Educação Fundamental.Parâmetros Curriculares Nacionais: apresentação dos temas transversais - ética.Vol. 8 Brasília: MEC, 1997.

.Parâmetros Curriculares Nacionais: Meio ambiente e Saúde. Vol. 9. Brasília: MEC, 1997.

CAÍNZOS, Manuel. Os principais temas transversais de formação integral. Madrid: SantillanoElf S.A., 1993.

CARVALHO, Isabel C. de M. A invenção ecológica: Narrativas e trajetórias da educação ambiental no Brasil. Porto Alegre: Editora da UFRS, 2001.

CASCINO, Fabio.Educação Ambiental: princípios, história e formação de professores. São Paulo: Editora SENAC, 1999.

DEHEINZELIN, Monique. Projetos. In: POR UM TRIZ. Arte e cultura: atividades e

projetos educativos. São Paulo: Paz e Terra, 1998.

DELEUZE, Gilles; GUATTARI, Félix. Micropolítica e segmentaridade. In: Mil platôs: capitalismo e esquizofrenia. Rio de Janeiro: Edição 34, Vol. 3, 1996.

DEMING, W.E. A Nova economia para a indústria o governo e a educação. Rio de Janeiro: Qualitymark, 1997.

DIAS, Genebaldo Freire.Educação ambiental: Princípios e prácticas.3. ed. São Paulo: Gaia, 1994.

FAZENDA. Ivani. Integração e interdisciplinaridade no ensino brasileiro: efetividade ou ideologia? São Paulo: Loyola, 1992.

(Org.). Práticas interdisciplinares na escola. 2.ed. São Paulo: Cortez, 1994.

FERNÁNDEZ, Carmen Enderle.Psicologia do desenvolvimento, processo evolutivo da criança.3. ed. Porto Alegre: Artes médicas, 1995.

FOUTO, A.R.F. O papel das universidades rumo ao desenvolvimento sustentável: das relações internacionais às práticas locais. Dissertação (Mestrado em Gestão e Políticas Ambientais Relações Internacionais do Ambiente), 2002. Disponível em:<http://campus.fct.unl.pt/campusverde/W_RIA_ARFF.doc>. Acesso em: 08 dez. 2005.

FREIRE, Paulo.Pedagogia do oprimido. 20. ed.Rio de Janeiro: Paz e Terra, 1992a.

Pedagogia da esperança: um reencontro com a pedagogia do oprimido. 6. ed. Rio de Janeiro: Paz e Terra, 1997.

Pedagogia da indignação: cartas pedagógicas e outros escritos. Apresentação de Ana Maria Araújo Freire. São Paulo: UNESP, 2000.

GADOTTI, Moacir.Pedagogia da Práxis.2. ed. São Paulo: Cortez, 1998.

GANDIN, Danilo.Planejamento como prática educativa. 3. ed. São Paulo: Loyola,1986.

GONZALES, Lucini F. Educação, Ética e Transversalidade. Caderno de Pedagogia. São Paulo: 1994.

GUATARRI, Félix. As três ecologias. Campinas: Papirus, 1999.

GUIMARÃES, Mauro. A dimensão ambiental na educação. Campinas: Papirus, 1995.

. A formação de educadores ambientais. Campinas: Papirus, 2004.

GUIMARÃES, Simone Sendin Moreira; INFORSATO, Edson do Carmo. Biologia no município de Piracicaba/SP. Rev. eletrônica Mestr. Educ. Ambient. ISSN 1517-1256, v. 25, julho a dezembro de 2010.

INEP № 226, DE 26 DE JULHO DE 2011. ENADE -Publicada no DOU no 249, Seção 1, de 29 de dezembro de 2010.

JAPIASSU, Hilton. Interdisciplinaridade e patologia do saber. Rio de Janeiro: Imago, 1976.

JUNGES, José Roque. Ética ambiental. Vale do Rio dos Sinos: Editora Unisinos, 2006.

KRAEMER, M.E.P. Gestão ambiental: Um Enfoque no Desenvolvimento Sustentável, 2004. Disponível em:<http://www.gestaoambiental.com.br/kraemer.php>. Acesso em: 28 nov. 2005. 


\section{REGEJATFSM MANÉIA \& KROHLING, v(7), no 7, p. 1540-1554, MAR-AGO, 2012.}

Rev. Elet. em Gestão, Educação e Tecnologia Ambiental (e-ISSN: 2236-1170)

KROHLING, Aloísio.Direitos Humanos Fundamentais: Diálogo Intercultural e Democracia.Editora Paulus, 1990.

. Ética da Alteridade e da Responsabilidade. Curitiba: Juruá, 2011.

. Anais da ABRAFI. Simpósio Belo Horizonte. 2011.

LEAVITT, Harold J.Psicology.Chicago: University of Chicago Press, 1964.

LEFF, E. Educação Ambiental e desenvolvimento sustentável. In: REIGOTA, M. (Org.). Verde cotidiano: o meio ambiente em discussão. Rio de Janeiro: DP\&A, 1999.

LOPES, Sonia. Bio completo e atualizado.São Paulo: Saraiva, 1998.

LÜCK, Heloisa.Pedagogía interdisciplinar: fundamentos teórico-metodológicos.Rio de Janeiro: Vozes, 1994.

LUCKESI, Cipriano Carlos. Filosofia da educação. São Paulo: Cortez, 1996. (Série de formação de professores)

MARTINS, Carlos. A pluralidade dos mundos e das condutas sociais: a contribuição de Bourdieu para a sociologia da educação. Em Aberto, Brasília, v.9, n.46, p.59-72, abr/jun. 1990.

MARTINS, José de Souza. O poder do atraso. São Paulo: Hucitec, 1998.

MINAYO, M.C. de S. O desafio do conhecimento: pesquisa qualitativa em saúde. 7. ed. São Paulo: Hucitec, 2000.

MOREIRA, Antonio F.B.; SILVA, Tomas Tadeu. Currículo, cultura e sociedade. 4. ed. São Paulo: Cortez, 2000.

MORETTO, Vasco Pedro. Construtivismo a produção do conhecimento em sala de aula. Rio de Janeiro: DP\&A, 2000.

MORIN, Edgar.A natureza humana: o paradigma perdido.4. ed. Lisboa: América, 1988.

.Complexidade e ética da solidariedade. In: CASTRO, G. de; CARVALHO, E. de A.; ALMEIDA, M.C. de (orgs.). Ensaios de complexidade. Porto Alegre: Sulina, 1997.

.O método I, a natureza da natureza. Portugal: Publicações Europa-América Ltda, 1997.

.Os sete saberes necessários à educação do futuro. São Paulo: Cortez, 2000.

.Saberes globais e saberes locais: o olhar transdisciplinar. Rio de Janeiro: Garamond, 2000b.

NERICl, Imidio Giuseppe. Didática: uma introdução. 2. ed. São Paulo: Atlas, 1988.

PENTEADO, Heloísa D. Meio ambiente e formação de professores. 3. ed. Coleção de Nossa Época, vol. 38. São Paulo: Cortez, 1994

PORLAN, R.; RIVERO, A. Conhecimento escolar: pedagogía investigação do meio. Caderno de Pedagogia.São Paulo: 1994.

PUJOL, R.M.; SANMARTI, N. Integração eixos transversais no currículo de Guix.1995. p. 213-214.

REIGOTA, Marcos. O que é educação ambiental. São Paulo: Brasiliense, 2006.

SANTOS, J.E.; SATO, M. (Orgs.) A contribuição da educação ambiental à caixa de Pandora. São Carlos: Rima, 2001.

SATO, Michèle. Educação para o Ambiente Amazônico. Tese (Doutorado), PPG-ERN/UFSCar, São Carlos,1997. 235 p.

- Educação Ambiental no Ensino Superior. Palestraproferida no Encontro Temático Educação Ambiental na UFPB. JoãoPessoa: PRODEMA \& REA/PB, 16 e 17 de Setembro de 1992.

SAVIANI, Dermeval.Escola e democracia. São Paulo: Cortez, Autores Associados, 1984.

SIMONETTI, Eliana; RAMOS, Murilo.A revolução dos bichos. Revista Veja. São Paulo, 18/04, 2001.

SOCA, Gener Mercedes.A formação Pedagógica Integral. Uma experiencia na formação do professor, 1999.

STURSA, Carla.Holística do meio ambiente na comunicação: uma abordagem dinâmica - inquisitiva.FAESA II, Vitória, 1999.

TAUCHEN et al. Gestão ambiental: um modelo da Faculdade Horizontina, 2005. In: XII SIMPEP. Bauru, SP. Disponível em: http://simpep.feb.unesp.br.

UNESCO/UNEP/IEP.Enviromental education: module for pre-service training of science teachers and supervisors for secondary schools. New York, 1983, (EnviromentalEducation Series, V. 7).

UNESCO. Vamos cuidar do Brasil: conceitos e práticas em educação ambiental na escola. (Coord. Soraia Silva de Mello, Rachel Trajber. Brasília: Ministério da Educação, Coordenação Geral de Educação Ambiental: Ministério do Meio Ambiente, Departamento de Educação Ambiental, 2007.

YUS, Rafael. Temas transversais de uma nova escola. Porto Alegre: Art. Méd. 1998. 